\title{
Gene expression profiling in chicken heterophils with Salmonella enteritidis stimulation using a chicken 44 K Agilent microarray Hsin-I Chiang ${ }^{\dagger 1}$, Christina L Swaggerty ${ }^{2}$, Michael H Kogut*2, Scot E Dowd ${ }^{3}$, Xianyao Li ${ }^{1}$, Igal Y Pevzner ${ }^{4}$ and Huaijun Zhou*1
}

\begin{abstract}
Address: ${ }^{1}$ Department of Poultry Science, Texas A\&M University, College Station, TX 77843, USA, ${ }^{2}$ United States Department of Agriculture, Agricultural Research Service, Southern Plains Agricultural Research Center, College Station, TX 77845, USA, ${ }^{3}$ Research and Testing Laboratories and Medical Biofilm Research Institute, Lubbock, TX 79407, USA and ${ }^{4}$ Cobb-Vantress, Inc., Siloam Springs, AR 72761, USA

Email: Hsin-I Chiang - samchiang@tamu.edu; Christina L Swaggerty - christi.swaggerty@ars.usda.gov; Michael H Kogut* - kogut@ffsru.usda.gov; Scot E Dowd - sdowd@pathogenresearch.org; Xianyao Li - xianyao@poultry.tamu.edu; Igal Y Pevzner - igal.pevzner@cobb-vantress.com; Huaijun Zhou* - hjzhou@poultry.tamu.edu

* Corresponding authors †Equal contributors
\end{abstract}

Published: 6 November 2008

BMC Genomics 2008, 9:526 doi:10.1/86/147|-2164-9-526
Received: 17 April 2008

Accepted: 6 November 2008

This article is available from: http://www.biomedcentral.com//47/-2/64/9/526

(C) 2008 Chiang et al; licensee BioMed Central Ltd.

This is an Open Access article distributed under the terms of the Creative Commons Attribution License (http://creativecommons.org/licenses/by/2.0), which permits unrestricted use, distribution, and reproduction in any medium, provided the original work is properly cited.

\begin{abstract}
Background: Salmonella enterica serovar Enteritidis (SE) is one of the most common food-borne pathogens that cause human salmonellosis and usually results from the consumption of contaminated poultry products. The mechanism of SE resistance in chickens remains largely unknown. Previously, heterophils isolated from broilers with different genetic backgrounds (SEresistant [line A] and -susceptible [line B]) have been shown to be important in defending against SE infections. To dissect the interplay between heterophils and SE infection, we utilized large-scale gene expression profiling.
\end{abstract}

Results: The results showed more differentially expressed genes were found between different lines than between infection (SE-treated) and non-infection (control) samples within line. However, the numbers of expressed immune-related genes between these two comparisons were dramatically different. More genes related to immune function were down-regulated in line $B$ than line $A$. The analysis of the immune-related genes indicated that SE infection induced a stronger, upregulated gene expression of line heterophils $A$ than line $B$, and these genes include several components in the Toll-like receptor (TLR) signaling pathway, and genes involved in T-helper cell activation.

Conclusion: We found: (I) A divergent expression pattern of immune-related genes between lines of different genetic backgrounds. The higher expression of immune-related genes might be more beneficial to enhance host immunity in the resistant line; (2) a similar TLR regulatory network might exist in both lines, where a possible MyD88-independent pathway may participate in the regulation of host innate immunity; (3) the genes exclusively differentially expressed in line A or line $B$ with SE infection provided strong candidates for further investigating SE resistance and susceptibility. These findings have laid the foundation for future studies of TLR pathway regulation and cellular modulation of SE infection in chickens. 


\section{Background}

Salmonellosis in humans often results from consuming foods contaminated with Salmonella. The reported incidences of human infections by Salmonella have dramatically increased since 1980, and at present are approximately 1,400,000 cases every year in the United States, which indirectly caused a significant economical loss due to medical costs and loss of productivity (Economic Research Service, http://www.ers.usda.gov/data/ Foodborneillness/). Salmonella enterica serovar Enteritidis (SE) is one of the most common Salmonella serotypes in many countries including the US, and is the main source of human salmonellosis through the consumption of contaminated poultry or shell eggs [1]. SE is a zoonotic pathogen and persists in the chicken cecum or ovaries without triggering clinical signs in the host. Salmonellosis in young chickens may cause high mortality as a result of severe diarrhea and dehydration, and include a greater risk of evolving into a carrier state [2-4].

Salmonella organisms can reach distal ileum and cecum in infected birds as the first place through oral route [5]. The outcome of an encounter with Salmonella is dependent on multiple factors including genetic background $[6,7]$. Although several studies have focused on the pathogenesis of SE in infected young chickens, the mechanism of SE resistance in healthy-carrier chickens remains unknown. Heterophils, the avian counterpart of mammalian neutrophils, are the most abundant leukocytes in the peripheral blood and are essential for initiating and modulating innate immunity [8]. Reducing the number of circulating heterophils significantly increases the susceptibility of young chickens to organ invasion by SE indicating a key role for peripheral blood heterophils in controlling SE infections in poultry [9]. It has also been reported that a large influx of heterophils is observed in the intestines of SE-infected chickens, indicating an increase in heterophils to the infection site contributes to defending against microbial infection $[9,10]$. Both studies of in vivo and in vitro SE-infected heterophils from different chicken lines also revealed that the up-regulated mRNA expression levels of interleukin (IL)-1 $\beta, I L-6, I L-8$ (also known as CXCLi2), IL-18, and anti-inflammatory cytokines transforming growth factor- $\beta 4$ (TGF- $\beta 4$ ) might be responsible for determining overall immune competence $[11,12]$. We have extensively characterized the innate immune response of two parental broiler lines (designated lines A and B). To date, we have shown increased in vitro heterophil function [13]. corresponds with an increased in vivo resistance to organ invasion by SE [11]. In addition, we have shown increased mRNA expression levels of pro-inflammatory cytokines in heterophils isolated from the more resistant line compared to the susceptible line $[11,12,14]$. Collectively, the data indicate differences in heterophil function and innate responsiveness are under genetic control.

Heterophils play an important role in providing increased resistance against $\mathrm{SE}$ infections in poultry. The objective of the present study was to examine SE resistance by dissecting the interplay between heterophils and SE. Large-scale expression profiling technology including microarrays has been successfully used to achieve this goal $[7,15-18]$. Microarray technology provides a more comprehensive, unbiased knowledge of all gene networks including members of gene families, ligands, receptors, and transcription factors [19]. Additionally, microarray analysis allows for the discovery of new genes and/or pathways previously not known to be involved in a specific host-pathogen interaction. In the present study, a chicken genome Agilent microarray [20] was used to profile differential gene expression in heterophils from two genetically distinct parental broiler lines (SE-susceptible [line B] and -resistant [line A]) following in vitro stimulation with SE. The objectives of this study were to discover genes or gene networks associated with SE resistance and to examine the genetic effects on defending against SE infections in chicken heterophils.

\section{Results \\ Identification of differentially expressed genes}

The genome-wide expression profiling of each element (probe) was assigned to four different comparisons as $\mathrm{AI} /$ AN (line A infection vs. non-infection), $\mathrm{BI} / \mathrm{BN}$ (line $\mathrm{B}$ infection vs. non-infection), AN/BN (non-infection line A vs. line $\mathrm{B}$ ) and $\mathrm{AI} / \mathrm{BI}$ (infection line $\mathrm{A}$ vs. line $\mathrm{B}$ ). In this context, the word infection refers to in vitro stimulation with SE. In the microarray analysis, genes differentially expressed at $P<0.001$ were considered statistically significant. The estimated false discovery rates at this level were controlled as $20 \%, 20 \%, 5 \%$, and $5 \%$ in each comparison of $\mathrm{AI} / \mathrm{AN}, \mathrm{BI} / \mathrm{BN}, \mathrm{AN} / \mathrm{BN}$, and $\mathrm{AI} / \mathrm{BI}$, respectively. The fold-change range of gene expression differences between the groups were 21.61 to $-4.21,9.60$ to $-6.67,29.16$ to 6.91 , and 33.30 to -4.57 in each comparison of $\mathrm{AI} / \mathrm{AN}, \mathrm{BI} /$ $\mathrm{BN}, \mathrm{AN} / \mathrm{BN}$, and $\mathrm{AI} / \mathrm{BI}$, respectively (see Additional files 1 , $2,3,4)$. The biological significance for each comparison was analyzed using the assigned cut-off expression ratio of 1.5 fold-change, and the direction of regulation. In general, more differentially expressed genes were found in the comparison between different lines (with 288 genes overlapped) than between infected and non-infected cells within line (with 51 genes overlapped) (Fig. 1). The regulation direction of these differentially expressed genes showed a dissimilar pattern in the comparisons of infected vs. non-infected cells between two lines. There were more genes up-regulated in the AI/AN (115 out of total 152 differentially expressed genes in $\mathrm{AI} / \mathrm{AN}$, and 48 out of total 173 differentially expressed genes in $\mathrm{BI} / \mathrm{BN}$ ). 


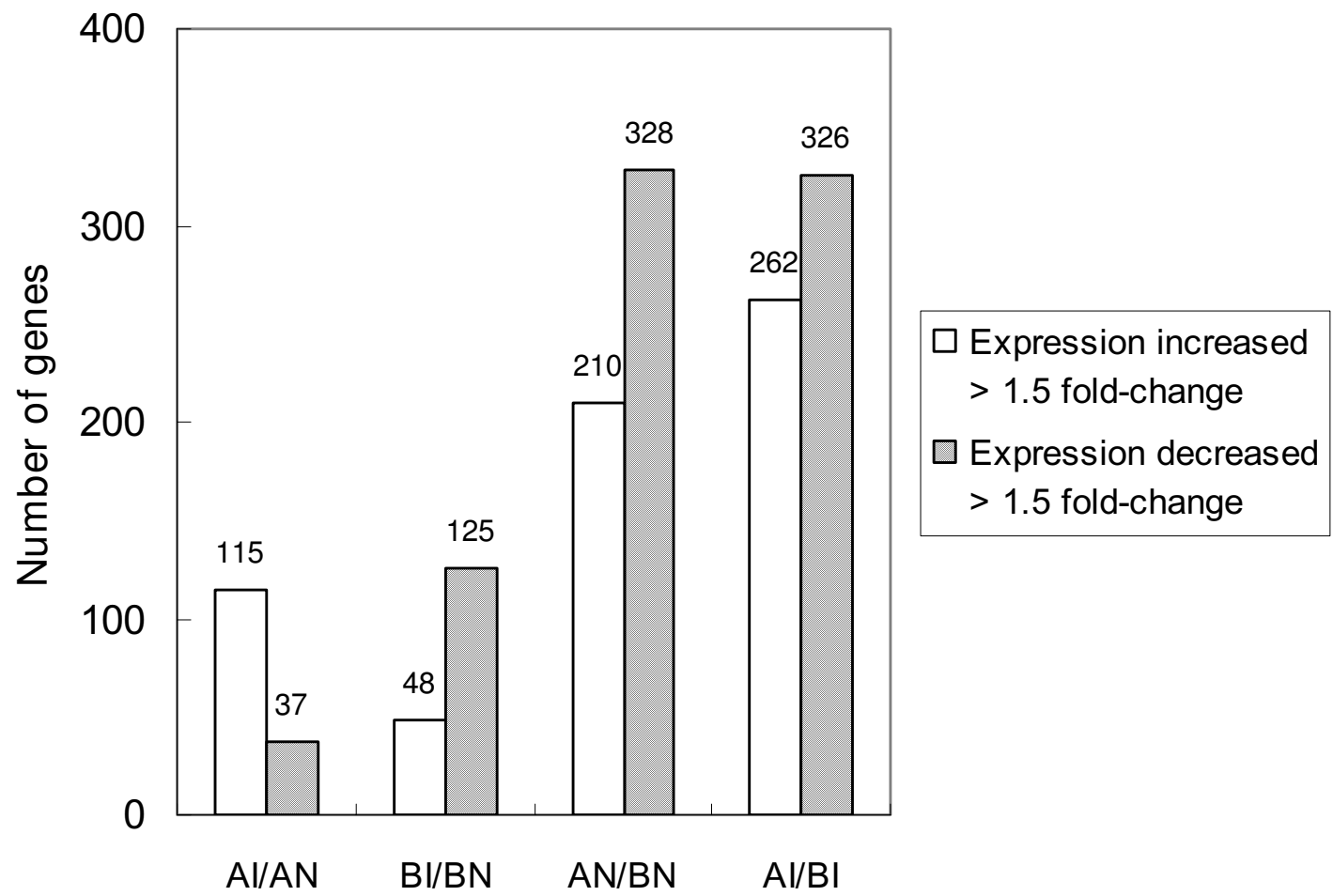

Figure I

Number of differentially expressed genes at four different comparisons. Cut-off: Larger than I.5 fold-change of increased or decreased expression with P-value smaller than $0.00 \mathrm{I}$.

However, more genes were down-regulated in the $\mathrm{BI} / \mathrm{BN}$ (37 out of total 152 differentially expressed genes in $\mathrm{AI} /$ AN, and 125 out of total 173 differentially expressed genes in $\mathrm{BI} / \mathrm{BN}$ ). A similar pattern of line A vs. line B comparisons was observed between infected and non-infected cells in terms of the number of up-regulated and downregulated genes. In general, line B showed higher mRNA level of gene expression than line A in both infected and non-infected cells.

\section{Gene ontology analysis}

The functional analysis was performed by identifying gene ontology (GO) terms (biological processes) of genes whose expression were significantly enriched among the pool of all differentially expressed genes. A Fisher-exact test was used to determine the enrichment of associated GO terms. Only significantly enriched $(P<0.05)$ GO terms are presented. In general, fewer significantly enriched GO terms were found in the comparison between infected and non-infected cells within line (Fig. 2A) than between genetic lines (Fig. 2B). In the comparisons between infected and non-infected cells, many functional terms were enriched in line $\mathrm{B}$, while none of the functional terms were found significantly enriched in the same comparison for line A. For the down-regulated genes in the $\mathrm{BI} / \mathrm{BN}$ comparison, many significantly enriched functional terms, including defense and immune response, and response to stress, were associated with the host defense system according to the GO term annotation [21]. For the line comparison, there were more enriched functional terms in the down-regulated genes than in the up-regulated genes. Interestingly, many enriched terms were overlapped between $\mathrm{AN} / \mathrm{BN}$ and $\mathrm{AI} / \mathrm{BI}$ with the similar abundance $(\%)$ of genes.

\section{Quantitative real-time PCR}

Validation of the microarray data was performed using quantitative real-time PCR (qRT-PCR). This allowed us to: (1) confirm the microarray results across different comparisons, and (2) validate selected immune-related genes associated with Salmonella infection of heterophils. Eight significantly expressed genes were randomly selected for qRT-PCR confirmation (see Additional file 5). The samples used in qRT-PCR were not the same as in the microarray study but were obtained according to the same experimental design. The results showed that most of the genes selected for qRT-PCR (13 incidences of differential expression) analysis were consistent with the results 


\section{Infection vs. Non-infection}

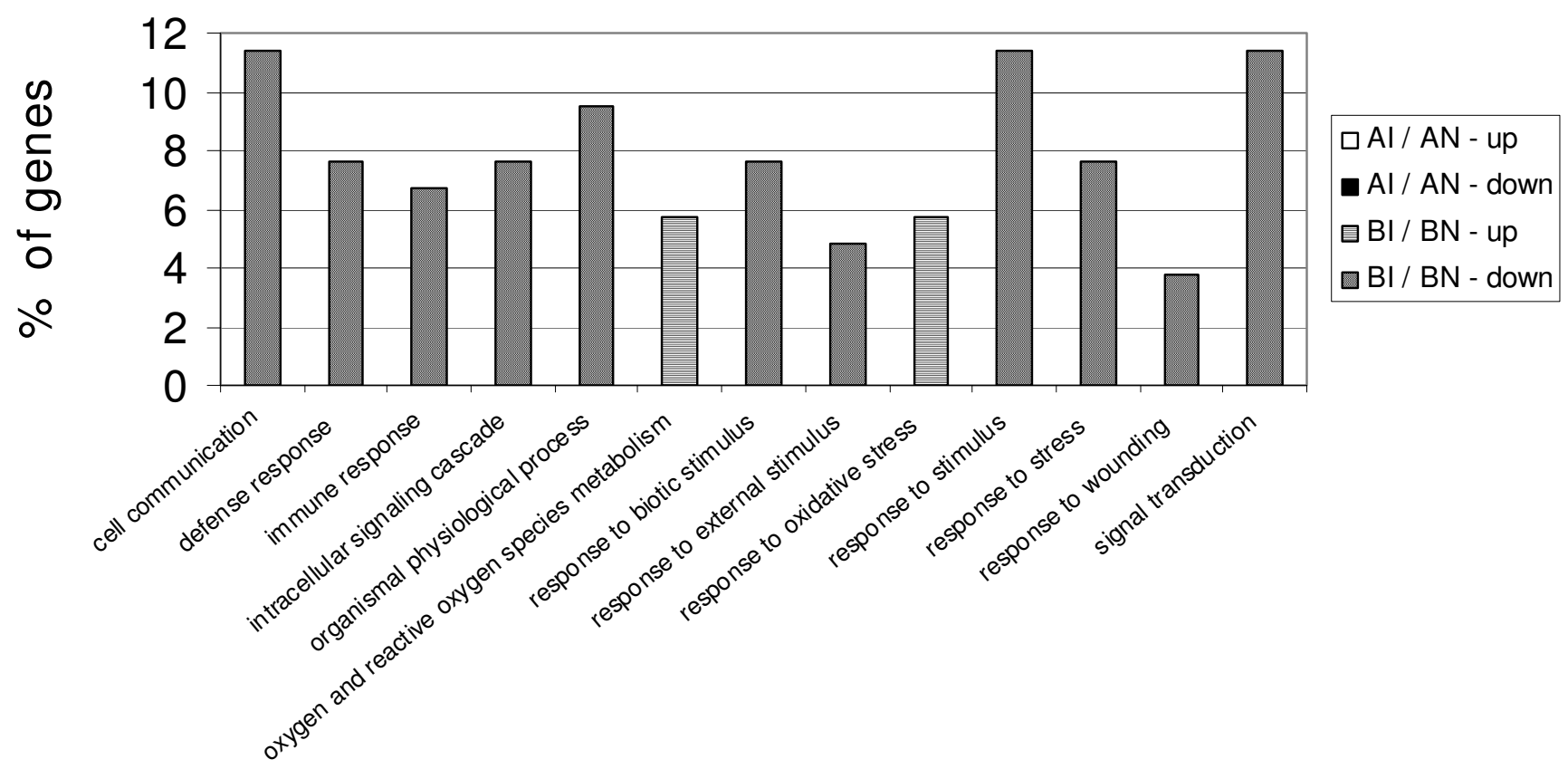

Figure 2

Gene ontology (GO) annotation of differentially expressed genes $(\boldsymbol{P}<\mathbf{0 . 0 0 I})$. A: Biological processes of up- or down-regulated genes between infection and non-infection treatments $(\mathrm{I} / \mathrm{N})$. B: Biological processes of up- or down-regulated genes between line $A$ and line $B$ heterophils $(A / B)$. The percentage represents the enriched-intensity of each term. The percentage represents the enriched-intensity of each term.

obtained from the microarray (14 incidences of differential expression) (see Additional file 6). For the four inconsistencies, the fold-changes from three were very close to the microarray results.

\section{Immune-related genes}

According to the information of the Gene Ontology Consortium's annotation [21], 426 immunologically-related genes (represented 542 probes in the array) were identified in this array. In order to study the host response to Salmonella infection and the role of genetic differences between the two lines, the list of immune-related genes were used to narrow down those previously identified differentially expressed genes $(P<0.001)$. Using the designated cut-off of 1.5 fold-change, 20 genes were found differentially expressed with SE infection (Table 1), where 12 genes were found in the comparison of line A and line $\mathrm{B}$ (Table 2). Several genes have duplicate probes in the array with consistent expression among comparisons. The number and regulation direction of immune-related genes showed a similar tendency to that of overall differentially expressed genes (Fig. 1B), in which there were more up-regulated genes in the AI/AN comparison, and more down-regulated genes in the $\mathrm{BI} / \mathrm{BN}$ comparison. In the comparison between the genetic lines, fewer immunerelated genes were identified with only a few genes that had differential expression overlapped between IA/IB and NA/NB. Since most immune-related genes showed positive fold-change ratio these data indicate that these genes have a stronger expression in line A than line $\mathrm{B}$ regardless of the SE infection.

\section{Utilization of the array}

All microarray results from this study were deposited in NCBI's Gene Expression Omnibus (GEO) database [22]. The accession numbers are: Platform, GPL4993; Series, GSE9416; Samples, GSM239322, GSM239330, GSM239336, GSM239337, GSM239347, GSM239349GSM239352, GSM239354-GSM23935456, GSM239358, GSM239370, GSM239372 and GSM23935473.

\section{Discussion}

Evaluation of host responses to bacterial infections in vitro using microarray technology has become one of the major research areas in the study of functional genomics. This technology allows us to characterize the comprehensive 
Table I: List of immune genes with differential expression $(P<0.00 I)$ between infection $(I)$ and non-infection $(N)$ treatment

\begin{tabular}{|c|c|c|c|}
\hline Accession No. & Gene Name & Al/ANa fold-change & $B I / B N^{b}$ fold-change \\
\hline AJ720630 & Antizyme inhibitor I (AZINI) & 2.59 & - \\
\hline AJ851659 & CD80 antigen & 3.85 & - \\
\hline YI5006 & Interleukin-I beta (ILI $\beta$ ) & 3.40 & - \\
\hline AJ309540 & Interleukin 6 (IL6) & 11.39 & 8.96 \\
\hline AJ56420I & Interleukin I2B (ILI2B) & 3.19 & 2.71 \\
\hline AJ720504 & Toll-like receptor 7 (TLR7) & -4.21 & -5.78 \\
\hline BX930367 & PREDICTED: bactericidal/permeability-increasing protein & -2.01 & -2.25 \\
\hline CR390308 & Glioma Amplified Sequence 4I & -1.90 & -1.88 \\
\hline L34553 & Chemokine (C-C) ligand 4 (CCL4) & 7.30 & 3.59 \\
\hline M16199 & Interleukin 8 (IL8) & 7.40 & 4.03 \\
\hline M64990 & Prostaglandin-endoperoxide synthase 2 (PTGS2) & 3.14 & 3.19 \\
\hline YI497I & CXC chemokine $K 60(K 60)$ & 8.93 & 4.12 \\
\hline AFI76086 & Similar to NUMB protein (NUMB) & - & -2.29 \\
\hline AF335427 & Nuclear factor, interleukin 3 regulated & - & -1.97 \\
\hline AJ639839 & Similar to immunoglobulin-like receptor B4 & - & -5.55 \\
\hline Aj85I 768 & Interleukin-I receptor-associated kinase 2 (IRAK2) & - & -2.05 \\
\hline AY621307 & Beta-defensin 5 (GAL9) & - & -1.80 \\
\hline$B U 133261$ & $\begin{array}{l}\text { Similar to Inhibitor of nuclear factor kappa-B kinase epsilon subunit (IKBKE/ } \\
\text { IKK- } \varepsilon \text { ) }\end{array}$ & - & -5.18 \\
\hline BU265026 & TIR domain containing adaptor inducing interferon-beta (TRIF/TICAMI) & - & -1.96 \\
\hline CR338732 & TNF receptor-associated factor 7 (TRAF7) & - & -1.62 \\
\hline
\end{tabular}

a,: The dash ("-") means that the expression differences were less than 1.5 fold. When the ratio (AI/AN) is smaller than I, the ratio -(AN/AI) is given.

b,: The dash ("-") means that the expression differences were less than I.5 fold. When the ratio (BI/BN) is smaller than I, the ratio -(BN/BI) is given.

host response(s) to complex pathogen stimuli under different experimental conditions. There has been a rapid increase in studies reporting the host response to Salmonella in chickens $[2,23]$. While most of the recent studies focus on profiling gene expression in immunologicallyrelated tissues $[15,16,18,24]$, the present study is the first to examine the response of a chicken innate immune leukocyte, the heterophil, to SE using microarray technology. Based on earlier findings, one hour post infection was selected as the point at which the peak cytokine mRNA expression levels were observed with in vitro SE stimula- tion in the two lines [14]. More time points following SE exposure to heterophils would provide interesting information regarding the kinetics of the host-pathogen interaction.

The FDR is used to control false positives in a declared significant gene in microarray studies. There are several factors affecting FDR: (1) the proportion of truly differentially expressed genes; (2) the distribution of true differences; (3) measurement variance; and (4) sample size [25]. Of these factors, the proportion of truly differen-

Table 2: List of immune genes with differential expression $(P<0.001)$ between chicken lineages $A$ and $B$

\begin{tabular}{|c|c|c|c|}
\hline Accession No. & Gene Name & Al/B |a fold-change & AN/BNb fold-change \\
\hline AFI76086 & Similar to NUMB protein (NUMB) & 2.18 & - \\
\hline AJ719428 & TNF receptor-associated protein I (TRAPI) & -1.60 & - \\
\hline TC207578 & Immunoglobulin-like receptor $\lg \mid-37$ & 1.93 & - \\
\hline U97157 & Lunatic fringe homolog (LFNG) & 1.89 & - \\
\hline CD735422 & B-G V-region-like B-G antigen (B-G) & 1.80 & 1.57 \\
\hline L34552 & CC Chemokine (CCLIL2) & 1.63 & 1.62 \\
\hline U20338 & Interferon regulatory factor 7 (IRF7) & 2.03 & 2.40 \\
\hline AF082329 & Caspase 6, apoptosis-related cysteine peptidase (CASP6) & - & -2.68 \\
\hline AF320331 & Interferon regulatory factor 4 (IRF4) & - & 2.15 \\
\hline CV858509 & TNF receptor-associated factor 2 (TRAF2) & - & 1.66 \\
\hline L39766 & Interferon regulatory factor I (IRFI) & - & 2.01 \\
\hline Y 12012 & CD4 antigen (CD4) & - & 1.71 \\
\hline
\end{tabular}

a,: The dash ("-") means that the expression differences were less than 1.5 fold. When the ratio $(\mathrm{Al} / \mathrm{BI})$ is smaller than I, the ratio -(BI/AI) is given. b,: The dash ("-") means that the expression differences were less than 1.5 fold. When the ratio (AN/BN) is smaller than I, the ratio -(BN/AN) is given. 
tially expressed genes has the most significant effect on FDR [25]. The proportion of truly differentially expressed genes depends on the biological questions being addressed. Obviously, truly differentially expressed genes from the comparison between infection vs. non-infection and the comparison between line $\mathrm{A}$ and line $\mathrm{B}$ in the present study would be different. Therefore, using the same FDR for these two comparisons might miss many false negative genes if the proportion of truly differentially expressed genes in that comparison was small. In that case, using same cut-off of $P$-value is more appropriate than FDR although it is not optimal.

The microarray experimental design used in this study provided direct comparisons to identify differentially expressed genes due to SE infection (infection or noninfection) or genetic differences (line A or B). More differentially expressed genes were detected in the comparisons between the lines compared to that observed between SE infected and non-infected cells. These data indicate there may be an intrinsic genetic difference between line $\mathrm{A}$ and $\mathrm{B}$ chickens. Line A chickens have a stronger immune response against in vivo bacteria challenge than line $\mathrm{B}$ chickens [10], however, no further study has been conducted. In addition, fewer differentially expressed genes in the comparison between infected and non-infected cells within line may also be due to the limited variance contributed by host response associated with SE infection at one time point ( $1 \mathrm{~h}$ post infection). The direction of gene regulation revealed that line $\mathrm{A}(\mathrm{AI} / \mathrm{AN})$ had less down-regulated genes, but more up-regulated genes compared to line $\mathrm{B}(\mathrm{BI} / \mathrm{BN})$. Interestingly, similar patterns were observed on the expressional direction of immune-related genes (Table 1). Given that line A chickens are more resistant to SE than line $\mathrm{B}$, it is possible that the enhanced SEresistance is associated with a different host response in terms of both a higher number of up-regulated immunerelated genes accompanied by fewer down-regulated genes.

\section{GO terms enrichment analysis}

The analysis of enriched GO terms allowed us to discover significant categories that could be overlooked when evaluating individual genes. The enriched GO terms could aid in interpreting the dominant functions controlled by differentially expressed genes. Although the higher number of identified GO terms might be positively correlated to more differentially expressed genes identified, the regulation direction of genes showed a remarkable difference as most enriched GO terms were composed of down-regulated genes in all comparisons.

No specific functional term (biological process) was significantly enriched with SE infection in the comparison of $\mathrm{AI} / \mathrm{AN}$, while several functional terms associated with defense systems were found from down-regulated genes in the $\mathrm{BI} / \mathrm{BN}$ comparison. The annotations of these terms suggest that line B may be more vulnerable to SE infections due to the suppressed functions on prevention or recovery from damages caused by infection. The results of the functional analysis further supported the results of expressional direction of immune-related genes, in which down-regulated genes (functional terms) with SE infection might be associated with the immuno-inefficiency observed in line B.

The comparison between different lines showed that most enriched functions had higher expression in line $\mathrm{B}$ than line A on both infected and non-infected cells. This suggested that these functions are not immune-related, and therefore the higher expression in line B might not benefit the host defense system. Although only three functions showed higher expression in line $\mathrm{A}$, one of these functions named 'response to stress' might benefit line A by remaining normal under exposure to infections. Several functional terms related to metabolism (e.g. cellular metabolism, primary metabolism, and protein metabolism) were down-regulated in line A with SE infection. Although heterophils are well known as primary phagocytes in immune system, there might be a complicated interaction between the immune system and metabolism [26]. It is possible that the highly expressed functions in line B may serve as an advantage over other performances in different desired traits. More studies are needed in order to understand the effects of the line differences on other parameters.

\section{Analysis of immune-related genes}

One of the key objectives of this study was to identify novel candidate genes associated with Salmonella resistance in chickens. The genetic variance contributing to the immune function only consist of a part of the whole genetic variance which is the overall genetic difference between line A and B. There were more differentially expressed genes in the comparisons between the two lines (538 and 588 genes in $\mathrm{AN} / \mathrm{BN}$ and $\mathrm{AI} / \mathrm{BI}$, respectively) than observed in the comparisons between the infected and non-infected cells (152 and 173 genes in $\mathrm{AI} / \mathrm{BI}$ and AN/BN, respectively). However, more immune-related genes were found in the comparisons between the infection and non-infection pairings (12 and 17 genes in $\mathrm{AI} / \mathrm{BI}$ and $\mathrm{AN} / \mathrm{BN}$, respectively) than between the two lines ( 7 and 8 genes in $\mathrm{AI} / \mathrm{BI}$ and $\mathrm{AN} / \mathrm{BN}$, respectively).

Numerous genes associated with immune function were found in both $\mathrm{AI} / \mathrm{AN}$ and $\mathrm{BI} / \mathrm{BN}$ pairing with a slightly higher fold-change in gene expression in $\mathrm{AI} / \mathrm{AN}$ than $\mathrm{BI} /$ $B N$. These genes included the cytokines $I L-1 \beta$ and $I L-6$, and the chemokines IL-8 (CXCLi2), CCL4 and K60 (also known as CXCLi1). Cytokines and chemokines are essen- 
tial for an effective innate immune response [27]. These data confirm and support earlier studies showing the higher expression of these signaling molecules in resistant line A are more important for their role in recruiting heterophils to the site of SE infection and pathogen clearance [28], and initiating the signaling cascades that promote a pro-inflammatory cytokine/chemokine response [16].

The effect of the MHC on determining immunity to Salmonella is described in the chicken [29,30]. There is a polymorphism (Lys148 $\rightarrow$ Met148) in the MHC I $\alpha 2$ domain that is associated with bacterial load in the spleen following an SE challenge [31]. Interestingly, several genes involved in MHC II system were differentially expressed in the present study. These genes included CD80, MHC II $\beta$ chain (accession no. U02881), c-KIT (v-kit Hardy-Zuckerman 4 feline sarcoma viral oncogene, accession no. D13225), $B-G$ and CD4. CD80, MHC II $\beta$ chain $(P=$ $0.005)$ and $c$-KIT $(P=0.036)$ were up-regulated in the comparisons of $\mathrm{AI} / \mathrm{AN}$, and the expression of $B-G$ and $C D 4$ were higher in line $A$ than line $B$ on both infected and non-infected cells. Functionally, the CD80 antigen is a surface molecule that co-regulates with another surface molecule, CD86, to provide a co-stimulating signal for Thelper cell activation [32,33]. On the other hand, c-KIT is a stem cell factor receptor that is co-expressed with MHC II to sustain T-helper cell development [34]. Heterophils have never been shown to have a role in antigen presentation and subsequent development of an acquired immune response; however, these data are indicative that heterophils may actually have such a role and future experiments will be conducted to assess this possibility.

Defensins are small peptides composed of cysteine-rich cationic molecules with broad-spectrum antimicrobial activity against bacteria, fungi and enveloped viruses [35]. One of the families, namely $\beta$-defensins, is widely accepted as an important component for the hosts' immune system. It has been suggested that avian $\beta$ defensins play a significant role in the avian innate defense system since heterophils lack an oxidative killing mechanisms [36]. To date, $14 \beta$-defensin genes, known as gallinacin (GAL) 1, 1A, 2-13, are described in chickens [37-39]. In the present study, SE infection suppressed the gene expression of $\beta$-defensin 5 (GAL 9) on line B heterophils, while no significant effect was observed on line A heterophils. GAL 9 has stronger antimicrobial activity against Salmonella serovars than GAL 4 and 7 [40]. It is possible that repression of GAL 9 is related to the impaired SE-resistance in the susceptible line and lends itself as a potential candidate gene for selecting poultry with increased resistance against SE.

The TLR signaling pathway plays a critical role for elevating host immune responses by sensing pathogen-associ- ated molecular patterns (PAMPs). Several genes associated with the TLR pathway have been reported to respond to Salmonella infection [12,41-44]. In the present study, two novel candidate adaptors, IKK- $\varepsilon$ (inhibitor of nuclear factor kappa-B kinase epsilon subunit) and TRIF (TIR domain containing adaptor inducing interferon-beta), were found repressed exclusively in BI/BN. IKK- $\varepsilon$ (also know as IKK epsilon or IKK-i) is an IKK homologue but not in components of IKK complex $[45,46]$. Although the underlying mechanisms remain elusive, it suggests that IKK- $\varepsilon$ plays a role in the activation of IRF3 and NF-kB by involving TANK-binding kinase 1 (TBK1) [47-50]. TRIF is an adaptor of the MyD88-independent pathway that leads to interferon (IFN) $\beta$ production, and the downstream cascade of TRIF is directly regulated by the adaptors IKK- $\varepsilon$ and TBK1 [51]. Interestingly, the co-repression of TRIF and $I K K-\varepsilon$ in line B observed in the current study suggests an important role for MyD88-independent pathway in host defense. A few genes involved in the TLR pathway were not significant since a stringent cut-off $P$-value established, even though the $P$-values of these genes approached 0.001 . While controlling false discovery rate is one of major objectives for microarray analysis, false negative might be an issue. In reality, it is possible that the lack of TLR-related expressed genes may in fact be one of the findings lost using stringent FDR criteria. These specific genes include receptors (TLR4, TLR15) and adaptors (MD-2 like, MKK3, NFkB-1) with $P$-values smaller than 0.05 , and fold-changes larger than 1.5 in the comparisons between the infected and non-infected cells. Collectively, these findings support our assumption that the TLR pathway is, but probably not the only one, involved in altering host defense system to SE infection through a response of releasing signaling molecules differently as seen in cytokines and chemokines.

Most immune-related genes showed stronger expression in line A heterophils than in line B heterophils regardless of the SE infection. It is unclear if these genes are responsible for the stronger induction of immune response in the resistant line. Numb is an inhibitor of the notch signaling pathway that maintains normal cell-to-cell communication, cell fate specification and tissue regeneration $[52,53]$. In the current study, the expression of numb was suppressed with SE infection in line B, while there was a significant up-regulation in the $\mathrm{AI} / \mathrm{BI}$. Given that line $\mathrm{B}$ showed down-regulation in the function of cell communication with SE infection, it is possible that the suppressed numb in line B indirectly retards the host immune network through impaired cell communication.

\section{Conclusion}

In summary, the results from this study demonstrate that higher expression of immune-related genes is more beneficial to enhance the host response against SE infection. 
The immune deficiency in the susceptible line is likely due to suppressed functions in recovering from cellular changes induced by SE infection. The genes exclusively differentially expressed in the $\mathrm{AI} / \mathrm{AN}$ or $\mathrm{BI} / \mathrm{BN}$ in the study has provided strong candidates for further investigation of disease resistance and susceptibility to SE infection in chickens, respectively. The identified immune-related genes also suggested a similar TLR regulatory network might exist in both lines, where a possible MyD88-independent pathway may participate in the regulation of host innate immunity in line B. Finally, the MHC II system might be important to initiate T-helper cell activation for the host defense.

To our knowledge, this is the first report to profile global gene expression in chicken heterophils with in vitro Salmonella infection. It is also expected that candidate genes discovered from this study along with the increasing information will add more genes to the chicken immune gene database. Although an in vivo study might be desirable to add additional insights regarding the interplay between heterophils and SE, the findings in this study have made an indispensable contribution to characterize the role of heterophils in the host immune system, and laid a solid foundation to further study the role of host genetics and resistance against Salmonella.

\section{Methods}

\section{Experimental chickens}

The two distinct parental meat-type broiler lines used in this study were obtained from a commercial company. To maintain confidentiality, the lines were designated $\mathrm{A}$ and B. At the day of hatch, chickens were placed in floor pens (8 feet) containing wood shavings, provided supplemental heat, water, and a balanced, un-medicated corn and soybean meal based chick starter diet ad libitum. The feed was calculated to contain $23 \%$ protein and $3200 \mathrm{kcal}$ of metabolized energy $/ \mathrm{kg}$ of diet, and all other nutrient rations met or exceeded the standards established by the National Research Council (1994). Animal experiments were conducted according to regulations established by the United States Department of Agriculture animal care and use committee (\#2007003) and overseen by Dr. J. A. Byrd, attending veterinarian.

\section{Bacteria}

A poultry isolate of SE (\#97-11771) was obtained from the National Veterinary Services Laboratory (Ames, IA) and approved by the United States Department of Agriculture (USDA). SE was cultured in tryptic soy broth (Difco Laboratories, Becton Dickinson Co., Sparks, $\mathrm{MD})$ overnight at $41^{\circ} \mathrm{C}$. Stock SE $\left(1 \times 10^{9}\right.$ colony forming units $[\mathrm{cfu}] / \mathrm{ml}$ ) was prepared as previously described [13].

\section{Heterophil isolation}

Heterophils were isolated from a pooled collection of peripheral blood from 6 -day-old chickens $(\mathrm{n}=100$ for each line). Blood was collected on four separate occasions on age-matched, straight-run chickens. Following blood collection, heterophils were isolated as previously described [12]. Briefly, blood from chickens was collected in vacutainer tubes containing disodium ethylenediaminetetraacetic acid (EDTA) (BD vacutainer, Franklin Lakes, NJ) and mixed thoroughly. The blood and EDTA for each line was pooled and diluted 1:1 with RPMI 1640 media containing $1 \%$ methylcellulose and centrifuged at $40 \mathrm{~g}$ for $15 \mathrm{~min}$ at $4^{\circ} \mathrm{C}$. The supernatant was transferred to a new conical tube and diluted with $\mathrm{Ca}^{2+-}$ and $\mathrm{Mg}^{2+}$-free Hanks balanced salt solution (1:1), layered onto discontinuous Histopaque $^{\circledast}$ gradients (specific gravity 1.077 over 1.119) and centrifuged at $190 \mathrm{~g}$ for one $\mathrm{h}$ at $4{ }^{\circ} \mathrm{C}$. The histopaque layers were collected, washed with RPMI 1640 (1:1) and pelleted at $485 \mathrm{~g}$ for $15 \mathrm{~min}$ at $4{ }^{\circ} \mathrm{C}$. The cells were then resuspended in fresh RPMI 1640, counted on a hemacytometer, and diluted to $1 \times 10^{7} / \mathrm{ml}$ in RPMI. All tissue culture reagents and chemicals obtained from Sigma Chemical Company, St. Louis, MO, unless noted otherwise.

\section{Total RNA Isolation}

Heterophils $\left(1 \times 10^{7}\right)$ were treated with $300 \mu \mathrm{l}$ RPMI or $\mathrm{SE}$, for $1 \mathrm{~h}$ at $39^{\circ} \mathrm{C}$ on a rotary shaker at the ratio of multiplicity of infection $=20$. Treated heterophils were pelleted, washed with RPMI ( $485 \times g$ for $15 \mathrm{~min}$ at $4{ }^{\circ} \mathrm{C}$ ), the supernatant discarded, the cells re-suspended in lysis buffer (Qiagen RNeasy mini RNA extraction kit, Qiagen Inc., Valencia, CA), and frozen. The lysed cells were transferred to QIAshredder homogenizer columns and centrifuged for $2 \mathrm{~min}$ at $\geq 8000 \times g$. Total RNA was extracted from the homogenized lysate according to the manufacturer's instructions, eluted with $50 \mu \mathrm{l}$ RNase-free water and stored at $-80^{\circ} \mathrm{C}$.

\section{Microarray experiment design}

A dual color, balanced design was used to provide four different comparisons: $\mathrm{AI} / \mathrm{AN}, \mathrm{BI} / \mathrm{BN}, \mathrm{AN} / \mathrm{BN}$ and $\mathrm{AI} / \mathrm{BI}$. Four biological replicates were conducted in each comparison and the dye balance was used throughout in order to prevent the dye-bias during the sample labeling.

\section{Labeling and hybridization}

The integrity of total RNA samples was confirmed using Agilent Bioanalyzer 2100 Lab-on-chip system (Agilent Technologies, Palo Alto, CA, USA). Five hundred nanograms (ng) of total RNA were reverse-transcribed to cDNA during which a T7 sequence was introduced into cDNA. T7 RNA polymerase-driven RNA synthesis was used for the preparation and labeling of RNA with $\mathrm{Cy} 3$ (or Cy5) dye. The fluorescent cRNA probes were purified using Qiagen RNeasy Mini Kit (Qiagen Inc., Valencia, CA), and 
an equal amount (825 ng) of Cy3 and Cy5 labeled cRNA probes were hybridized on a $44 \mathrm{~K}$ chicken Agilent array (GEO accession: GSE9416). The hybridized slides were washed using a commercial kit package (Agilent Technologies, Palo Alto, CA, USA) and then scanned using Genepix 4100A scanner (Molecular Devices Corporation, Sunnyvale, CA) with the tolerance of saturation setting of $0.005 \%$.

\section{Microarray data collection and analysis}

For each channel, the median of the signal intensity and local background values were used. A Locally Weighted Linear Regression (LOWESS) normalization was applied to remove signal intensity-dependent dye bias for each array using $\mathrm{R}$ program. The normalized data was analyzed using commercial SAS 9.1.3 program (SAS Institute Inc. Cary, NC) with mixed model analysis. The mixed model used to identify significantly differentially expressed genes was:

$$
\mathrm{Y}_{\mathrm{ijklm}}=\mu+\mathrm{T}_{\mathrm{i}}+\mathrm{L}_{\mathrm{j}}+\mathrm{D}_{\mathrm{k}}+\mathrm{S}_{\mathrm{l}}+\mathrm{T}^{*} \mathrm{~L}_{\mathrm{ij}}+\mathrm{e}_{\mathrm{ijklm}}
$$

Where $Y_{\mathrm{ijklm}}$ represents each normalized signal intensity; $\mu$ is an overall mean value; $T_{i}$ is the main effect of treatment (SE infection) $i$; $L_{j}$ is the main effect of chicken line $j ; D_{k}$ is the main effect of dye $k ; S_{1}$ is the random effect of slide $l_{\text {; }}$ $\mathrm{T}^{*} \mathrm{~L}_{\mathrm{ij}}$ is the interaction between treatment and line; and $e_{i j k l m}$ is a stochastic error (assumed to be normally distributed with mean 0 and variance $\sigma^{2}$ ). An approximate F test on least-square means was used to estimate the significance of difference for each gene in each comparison where $P<0.001$ was considered to be statistically different. The false discovery rate ( $Q$ value) was calculated for each $P$-value using R program according to the Storey and Tibshirani method [54].

\section{Quantitative real-time PCR}

Total RNA (300 ng) from each sample (AI, AN, BI and BN) was used for cDNA synthesis with random hexamer primer of a Thermoscript RT-PCR system kit (Invitrogen, Carlsbad, CA) according to the manufacturer's manual. The cDNAs were quantified by qRT-PCR using ABI prism 7900HT system (Applied Biosystems, Foster, CA) with SYBR Green PCR Master Mix (Applied Biosystems, Foster, CA). The specific oligonucleotide primers were designed by PRIMER3 program [55]. The conditions of qRT-PCR amplification were: 1 cycle at $95^{\circ} \mathrm{C}$ for $10 \mathrm{~min}, 40$ cycles at $95^{\circ} \mathrm{C}$ for $15 \mathrm{~s}$ and $59^{\circ} \mathrm{C}$ for $1 \mathrm{~min}$. The chicken $\beta$-actin gene was used as the internal control. Dissociation curves were performed at the end of amplification for validating data quality. Each individual sample was run in triplicate and the average critical threshold cycle (Ct) was used for calculating relative quantification by fold-change and statistical significance.

\section{Bioinformatics}

An unreleased version of the High Throughput Gene Ontology Functional Annotation Toolkit (HTGOFAT, http://www.researchandtesting.com/Bioinformat ics.html) was utilized to assign updated Gene Ontology numbers [21], Enzyme Commission [56] numbers, mappings to Kyoto Encylopedia of Genes and Genomes (KEGG) Pathways [57] and updated definitions. Statistics related to over representation of functional categories were performed using a Fisher Exact statistic methodology similar to that described by Al-Shahrour et al [58]. In brief, differentially expressed genes $(P<0.001)$ were selected and separated based on regulation directions (up or down) in each comparison. Data mining to PubMed IDs was performed using a beta version module within HTGOFAT that searched PubMed abstracts using upon experimental conditions or terms (e.g. chicken and Salmonella) that co-occur with gene names and symbols that are represented within a given dataset. Additionally, differentially regulated genes were mapped to Protein Information Resource (PIR) keywords [59] and COG [60] functional annotations through the use of primary mappings with HTGOFAT and subsequent mapping and clustering using the Database for Annotation, Visualization and Integrated Discovery (DAVID) [61].

\section{Authors' contributions}

HC carried out the microarray experiments, analyzed data and drafted the manuscript. CS was responsible for heterophil isolation, in vitro stimulation, RNA isolation, and revision of the manuscript. MK contributed to experiment design and data interpretation. SD contributed to functional annotation and analyses. XL assisted in data processing. IP provided genetic lines. HZ designed the microarray, provided the concepts of the study, and revised the manuscript. All authors submitted comments, read and approved the final manuscript.

\section{Additional material}

\section{Additional file 1}

Differentially expressed genes in the comparison AI to AN. The file contains all differentially expressed $(\mathrm{P}<0.001$ with fold-change $>1.5$ or $<-$ 1.5) genes shown in the comparison between infected and non-infected cells within line A.

Click here for file

[http://www.biomedcentral.com/content/supplementary/14712164-9-526-S1.xls]

\section{Additional file 2}

Differentially expressed genes in the comparison $\mathrm{BI}$ to $\mathrm{BN}$. The file contains all differentially expressed $(\mathrm{P}<0.001$ with fold-change $>1.5$ or $<-$ 1.5) genes shown in the comparison between infected and non-infected cells within line $B$.

Click here for file

[http://www.biomedcentral.com/content/supplementary/14712164-9-526-S2.xls] 


\section{Additional file 3}

Differentially expressed genes in the comparison AN to BN. The file contains all differentially expressed $(\mathrm{P}<0.001$ with fold-change $>1.5$ or $<-1.5)$ genes shown in the comparison of non-infected cells between different lines.

Click here for file

[http://www.biomedcentral.com/content/supplementary/14712164-9-526-S3.xls]

\section{Additional file 4}

Differentially expressed genes in the comparison AI to BI. The file contains all differentially expressed $(\mathrm{P}<0.001$ with fold-change $>1.5$ or $<-$ $1.5)$ genes shown in the comparison of infected cells between different lines

Click here for file

[http://www.biomedcentral.com/content/supplementary/14712164-9-526-S4.xls

\section{Additional file 5}

Primers used for qRT-PCR. This file contains primers sequences and amplified PCR product sizes of genes chosen for qRT-PCR confirmation. Click here for file

[http://www.biomedcentral.com/content/supplementary/14712164-9-526-S5.doc]

\section{Additional file 6}

Expression differences found with the microarray compared with the qRT-PCR. This file contains expression differences found with the microarray compared with the qRT-PCR. Bold are differences in expression levels found with the microarray $(\mathrm{P}<0.001)$ as well as the qRT-PCR $(\mathrm{P}<$ $0.05)$.

Click here for file

[http://www.biomedcentral.com/content/supplementary/14712164-9-526-S6.doc]

\section{Acknowledgements}

The authors wish to thank Pete Kaiser for providing chicken cytokine and chemokine gene sequences; Fiona McCarthy and Shane burgess for annotating part of genes in the array.

\section{References}

I. Braden CR: Salmonella enterica serotype Enteritidis and eggs: a national epidemic in the United States. Clin Infect Dis 2006 43(4):5 I2-5I7.

2. Sadeyen JR, Trotereau J, Velge P, Marly J, Beaumont C, Barrow PA, Bumstead N, Lalmanach AC: Salmonella carrier state in chicken: comparison of expression of immune response genes between susceptible and resistant animals. Microbes Infect 2004, 6( I 4): | 278-| 286

3. Barrow PA, Huggins MB, Lovell MA, Simpson JM: Observations on the pathogenesis of experimental Salmonella typhimurium infection in chickens. Res Vet Sci 1987, 42(2): 194-199.

4. Van Immerseel F, De Buck J, De Smet I, Mast J, Haesebrouck F, Ducatelle R: Dynamics of immune cell infiltration in the caeca lamina propria of chickens after neonatal infection with a Salmonella enteritidis strain. Dev Comp Immunol 2002 26(4):355-364.

5. Berndt A, Wilhelm A, Jugert C, Pieper J, Sachse K, Methner U: Chicken cecum immune response to Salmonella enterica serovars of different levels of invasiveness. Infect Immun 2007 75(1 2):5993-6007.

6. Mastroeni $P$, Sheppard $M$ : Salmonella infections in the mouse model: host resistance factors and in vivo dynamics of bacte- rial spread and distribution in the tissues. Microbes Infect 2004, 6(4):398-405

7. van Hemert S, Hoekman AJ, Smits MA, Rebel JM: Gene expression responses to a Salmonella infection in the chicken intestine differ between lines. Vet Immunol Immunopathol 2006, I I 4(34):247-258.

8. Kogut MH, Genovese KJ, Lowry VK: Differential activation of signal transduction pathways mediating phagocytosis, oxidative burst, and degranulation by chicken heterophils in response to stimulation with opsonized Salmonella enteritidis. Inflammation 200I, 25(I):7-I5.

9. Kogut MH, Tellez GI, McGruder ED, Hargis BM, Williams JD, Corrier $D E$, DeLoach JR: Heterophils are decisive components in the early responses of chickens to Salmonella enteritidis infections. Microb Pathog I994, I 6(2):|4|-I5I.

10. Swaggerty CL, Ferro PJ, Pevzner IY, Kogut MH: Heterophils are associated with resistance to systemic Salmonella enteritidis infections in genetically distinct chicken lines. FEMS Immunol Med Microbiol 2005, 43(2): I49-I54.

II. Ferro PJ, Swaggerty CL, Kaiser P, Pevzner IY, Kogut MH: Heterophils isolated from chickens resistant to extra-intestinal Salmonella enteritidis infection express higher levels of proinflammatory cytokine mRNA following infection than heterophils from susceptible chickens. Epidemiol Infect 2004, I32(6): 1029-1037.

12. Swaggerty CL, Kaiser P, Rothwell L, Pevzner IY, Kogut MH: Heterophil cytokine mRNA profiles from genetically distinct lines of chickens with differential heterophil-mediated innate immune responses. Avian Pathol 2006, 35(2): I02-108.

13. Swaggerty CL, Pevzner IY, Lowry VK, Farnell MB, Kogut MH: Functional comparison of heterophils isolated from commercial broiler chickens. Avian Pathol 2003, 32(I):95-102.

14. Swaggerty CL, Kogut MH, Ferro PJ, Rothwell L, Pevzner IY, Kaiser P: Differential cytokine mRNA expression in heterophils isolated from Salmonella-resistant and -susceptible chickens. Immunology 2004, I I 3( I): I 39- | 48 .

15. Sarson AJ, Read LR, Haghighi HR, Lambourne MD, Brisbin JT, Zhou $H$, Sharif $S$ : Construction of a microarray specific to the chicken immune system: profiling gene expression in B cells after lipopolysaccharide stimulation. Can J Vet Res 2007, 7 I (2): 108-I I8.

16. Zhou H, Lamont S): Global gene expression profile after Salmonella enterica Serovar enteritidis challenge in two F8 advanced intercross chicken lines. Cytogenet Genome Res 2007, I I ( I-4): | $31-134$

17. Zhao SH, Kuhar D, Lunney JK, Dawson H, Guidry C, Uthe JJ, Bearson SM, Recknor J, Nettleton D, Tuggle CK: Gene expression profiling in Salmonella Choleraesuis-infected porcine lung using a long oligonucleotide microarray. Mamm Genome 2006, I 7(7):777-789.

18. van Hemert S, Hoekman AJ, Smits MA, Rebel JM: Immunological and gene expression responses to a Salmonella infection in the chicken intestine. Vet Res 2007, 38(I):5 I-63.

19. Rosenberger CM, Pollard AJ, Finlay BB: Gene array technology to determine host responses to Salmonella. Microbes and Infection 2001, 3(14-15):1353-1360.

20. Li X, Chiang HI, Zhu J, Dowd SE, Zhou H: Characterization of a newly developed chicken $44 \mathrm{~K}$ Agilent microarray. BMC Genomics 2008, 9:60.

2I. Ashburner M, Ball CA, Blake JA, Botstein D, Butler H, Cherry JM, Davis AP, Dolinski K, Dwight SS, Eppig JT, Harris MA, Hill DP, IsselTarver L, Kasarskis A, Lewis S, Matese JC, Richardson JE, Ringwald M, Rubin GM, Sherlock G: Gene ontology: tool for the unification of biology. The Gene Ontology Consortium. Nat Genet 2000, 25(I):25-29.

22. Barrett T, Troup DB, Wilhite SE, Ledoux P, Rudnev D, Evangelista C, Kim IF, Soboleva A, Tomashevsky M, Edgar R: NCBI GEO: mining tens of millions of expression profiles-database and tools update. Nucleic Acids Res 2007:D760-765.

23. Sadeyen JR, Trotereau J, Protais J, Beaumont C, Sellier N, Salvat G, Velge $P$, Lalmanach AC: Salmonella carrier-state in hens: study of host resistance by a gene expression approach. Microbes Infect 2006, 8(5): $1308-13 \mid 4$.

24. Smith J, Speed D, Hocking PM, Talbot RT, Degen WG, Schijns VE, Glass EJ, Burt DW: Development of a chicken 5 K microarray targeted towards immune function. BMC Genomics 2006, 7:49. 
25. Pawitan Y, Michiels S, Koscielny S, Gusnanto A, Ploner A: False discovery rate, sensitivity and sample size for microarray studies. Bioinformatics 2005, 2 I (13):3017-3024.

26. Matarese G, La Cava $A$ : The intricate interface between immune system and metabolism. Trends Immunol 2004, 25(4): 193-200.

27. Kaiser P, Poh TY, Rothwell L, Avery S, Balu S, Pathania US, Hughes S, Goodchild M, Morrell S, Watson M, Bumstead N, Kaufman J, Young JR: A genomic analysis of chicken cytokines and chemokines. J Interferon Cytokine Res 2005, 25(8):467-484.

28. Kogut MH, McGruder ED, Hargis BM, Corrier DE, Deloach JR: Characterization of the pattern of inflammatory cell influx in chicks following the intraperitoneal administration of live Salmonella enteritidis and Salmonella enteritidis-immune lymphokines. Poult Sci 1995, 74(I):8-I7.

29. Cotter PF, Taylor RL Jr, Abplanalp H: B-complex associated immunity to Salmonella enteritidis challenge in congenic chickens. Poult Sci 1998, 77(I2):|846-|85|.

30. Lamont SJ, Kaiser MG, Liu W: Candidate genes for resistance to Salmonella enteritidis colonization in chickens as detected in a novel genetic cross. Vet Immunol Immunopathol 2002, 87(34):423-428.

31. Liu W, Miller MM, Lamont SJ: Association of MHC class I and class II gene polymorphisms with vaccine or challenge response to Salmonella enteritidis in young chicks. Immunogenetics 2002, 54(8):582-590.

32. Tizard IR: Veterinary immunology: an introduction. 7th edition. Philadelphia: Saunders; 2004

33. O'Regan MN, Parsons KR, Tregaskes CA, Young JR: A chicken homologue of the co-stimulating molecule CD80 which binds to mammalian CTLA-4. Immunogenetics 1999 49(I):68-7I.

34. Ody C, Corbel C, Dunon D, Vainio O, Imhof BA: MHC class II and c-kit expression allows rapid enrichment of $\mathrm{T}$-cell progenitors from total bone marrow cells. Blood 2000, 96(1 2):3988-3990.

35. Lehrer RI, Ganz T: Defensins of vertebrate animals. Curr Opin Immunol 2002, I 4(I):96-I02.

36. Sugiarto $H$, Yu PL: Avian antimicrobial peptides: the defense role of beta-defensins. Biochem Biophys Res Commun 2004 323(3):72I-727.

37. Xiao Y, Hughes AL, Ando J, Matsuda Y, Cheng JF, Skinner-Noble D, Zhang G: A genome-wide screen identifies a single betadefensin gene cluster in the chicken: implications for the origin and evolution of mammalian defensins. BMC Genomics 2004, 5(I):56.

38. Lynn DJ, Higgs R, Gaines S, Tierney J, James T, Lloyd AT, Fares MA, Mulcahy G, O'Farrelly C: Bioinformatic discovery and initial characterisation of nine novel antimicrobial peptide genes in the chicken. Immunogenetics 2004, 56(3): I70-177.

39. van Dijk A, Veldhuizen El, Haagsman HP: Avian defensins. Vet Immunol Immunopathol 2008, I 24(I-2): I- I8.

40. Milona $\mathrm{P}$, Townes $\mathrm{CL}$, Bevan RM, Hall J: The chicken host peptides, gallinacins 4,7 , and 9 have antimicrobial activity against Salmonella serovars. Biochem Biophys Res Commun 2007 356(I): 169-174.

4I. Kaiser P, Rothwell L, Galyov EE, Barrow PA, Burnside J, Wigley P. Differential cytokine expression in avian cells in response to invasion by Salmonella typhimurium, Salmonella enteritidis and Salmonella gallinarum. Microbiology 2000, I46(Pt I 2):321 7-3226.

42. Wigley P, Hulme S, Rothwell L, Bumstead N, Kaiser P, Barrow P. Macrophages isolated from chickens genetically resistant or susceptible to systemic salmonellosis show magnitudinal and temporal differential expression of cytokines and chemokines following Salmonella enterica challenge. Infect Immun 2006, 74(2): |425-1430.

43. Kogut $M H$, Rothwell $L$, Kaiser $P$ : Differential regulation of cytokine gene expression by avian heterophils during receptor-mediated phagocytosis of opsonized and nonopsonized Salmonella enteritidis. J Interferon Cytokine Res 2003, 23(6):319-327.

44. Kogut MH, Swaggerty C, He H, Pevzner I, Kaiser P: Toll-like receptor agonists stimulate differential functional activation and cytokine and chemokine gene expression in heterophils iso- lated from chickens with differential innate responses. Microbes Infect 2006, 8(7): |866-|874.

45. Peters RT, Maniatis T: A new family of IKK-related kinases may function as I kappa B kinase kinases. Biochim Biophys Acta 200 I, I 47 I (2):M57-62.

46. Kishore N, Huynh QK, Mathialagan S, Hall T, Rouw S, Creely D, Lange G, Caroll J, Reitz B, Donnelly A, Boddupalli H, Combs RG, Kretzmer K, Tripp CS: IKK-i and TBK-I are enzymatically distinct from the homologous enzyme IKK-2: comparative analysis of recombinant human IKK-i, TBK-I, and IKK-2. J Biol Chem 2002, 277( I 6): I 3840- I 3847

47. Fitzgerald KA, McWhirter SM, Faia KL, Rowe DC, Latz E, Golenbock DT, Coyle AJ, Liao SM, Maniatis T: IKKepsilon and TBKI are essential components of the IRF3 signaling pathway. Nat Immunol 2003, 4(5):49I-496.

48. Chariot A, Leonardi A, Muller J, Bonif M, Brown K, Siebenlist U: Association of the adaptor TANK with the I kappa B kinase (IKK) regulator NEMO connects IKK complexes with IKK epsilon and TBKI kinases. J Biol Chem 2002, 277(40):37029-37036

49. Li Q, Verma IM: NF-kappaB regulation in the immune system. Nat Rev Immunol 2002, 2( I 0):725-734.

50. Nomura F, Kawai T, Nakanishi K, Akira S: NF-kappaB activation through IKK-i-dependent I-TRAF/TANK phosphorylation. Genes Cells 2000, 5(3): 191-202.

5I. Yamamoto M, Sato S, Hemmi H, Hoshino K, Kaisho T, Sanjo H, Takeuchi O, Sugiyama M, Okabe M, Takeda K, Akira S: Role of adaptor TRIF in the MyD88-independent toll-like receptor signaling pathway. Science 2003, 30 I(5633):640-643.

52. Lai EC: Notch signaling: control of cell communication and cell fate. Development 2004, I 3 I (5):965-973

53. Katoh $M$, Katoh M: NUMB is a break of WNT-Notch signaling cycle. Int J Mol Med 2006, I 8(3):5 I 7-52 I

54. Storey JD, Tibshirani R: Statistical significance for genomewide studies. Proc Natl Acad Sci USA 2003, I 00( I 6):9440-9445.

55. Rozen S, Skaletsky H: Primer3 on the WWW for general users and for biologist programmers. Methods Mol Biol 2000 , I 32:365-386.

56. Shah I, Hunter L: Visualization based on the Enzyme Commission nomenclature. Pac Symp Biocomput 1998: I42-152.

57. Ogata H, Goto S, Sato K, Fujibuchi W, Bono H, Kanehisa M: KEGG: Kyoto Encyclopedia of Genes and Genomes. Nucleic Acids Res 1999, 27(I):29-34

58. Al-Shahrour F, Diaz-Uriarte R, Dopazo J: FatiGO: a web tool for finding significant associations of Gene Ontology terms with groups of genes. Bioinformatics 2004, 20(4):578-580.

59. Wu CH, Huang H, Arminski L, Castro-Alvear J, Chen Y, Hu ZZ, Ledley RS, Lewis KC, Mewes HW, Orcutt BC, Suzek BE, Tsugita A, Vinayaka CR, Yeh LS, Zhang J, Barker WC: The Protein Information Resource: an integrated public resource of functional annotation of proteins. Nucleic Acids Res 2002, 30(I):35-37.

60. Tatusov RL, Fedorova ND, Jackson JD, Jacobs AR, Kiryutin B, Koonin EV, Krylov DM, Mazumder R, Mekhedov SL, Nikolskaya AN, Rao BS, Smirnov S, Sverdlov AV, Vasudevan S, Wolf YI, Yin JJ, Natale DA: The COG database: an updated version includes eukaryotes. BMC Bioinformatics 2003, 4:4l.

61. Dennis G Jr, Sherman BT, Hosack DA, Yang J, Gao W, Lane HC, Lempicki RA: DAVID: Database for Annotation, Visualization, and Integrated Discovery. Genome Biol 2003, 4(5):P3. 